\title{
Reduction of Salinity of Water Using Acrylamide-Based Polyampholyte
}

\author{
Elvis Fosso-Kankeu ${ }^{*}$, Hasan Varachia and Frans Waanders
}

\begin{abstract}
Polyampholytes are charged macromolecules, which carry both acidic and basic groups. These groups dissociate, leaving ions on chains and counter ions in solution, under appropriate conditions, such as in aqueous solutions. After ionization occurs, there are positively and negatively charged groups on the polymer chain. Polyampholytes are able to absorb high dosages of anions and cations adequately and would ultimately be the best alternative for the reduction of salinity in water. In this study polyampholites with different ratio of cationic groups were synthesized and tested for the removal of sulphate from solution.
\end{abstract}

High cationic Polyampholytes showed great sulphate absorption capacities and could remove $100 \%$ of sulphate content. These Polyampholytes are able to function on a relatively low dosage and over a short period of time. Polyampholytes may be a good solution towards the implementation of desalination plants.

Keywords - absorption, desalination, polyampholyte, Salinity.

\section{INTRODUCTION}

Water scarcity predictions estimate that by the year 2025 about $50 \%$ of the world's population will suffer from water scarcity, approximating 3.5 billion people. Furthermore, South Africa will however exceed the accessibility of economically consumable drinking water by or before 2025 . The immensely enduring trend of the growth of the population will inevitably place a further burden and strain on the requisite to clean water supplies, until or unless corrective mechanisms and techniques are established. [1]

The combustion of fossil fuel and metallurgical roasting processes release sulphates into the atmosphere as sulphur dioxide. Sulphur dioxide is converted to dilute sulphuric acid and by precipitation falls as acid rain contaminating surface water and resulting in high concentrations of sulphate in water. [2]

Manuscript received October 03, 2018

E. Fosso-Kankeu is with the Water Pollution Monitoring and Remediation Initiatives Research Group and the School of Chemical and Minerals Engineering at the North-West University, Potchefstroom, South Africa.

Hasan Varachia is with the Water Pollution Monitoring and Remediation Initiatives Research Group and the School of Chemical and Minerals Engineering at the North-West University, Potchefstroom, South Africa.

F.B. Waanders is with the Water Pollution Monitoring and Remediation Initiatives Research Group and the School of Chemical and Minerals Engineering at the North-West University, Potchefstroom, South Africa.
Mines contribute immensely to water pollution and are the main source of sulphate addition to water. Chemical pollution is partly due to the dispersion of mine waste in the environment. Coal preparation, acid mine drainage effluents and other anthropogenic methods and activities mostly contain elevated concentration of calcium, magnesium, sulphate and sodium. [3] Desalination is becoming a realistic alternative for coastal users as technology improves. [1] With only $3 \%$ of all available water on the planet being fresh water, seawater is the most abundant available source of drinking water and water for industrial use in many regions, and reverse osmosis is the dominant technology for production of drinking water. Seawater has a relatively high salinity, which sets a limit for the recovery by reverse osmosis at $30-50 \%$. [4] This fundamentally leads to the need for improved salinity reduction techniques.

The drinking water from natural sources in coastal Bangladesh has become contaminated by varying degrees of salinity due to saltwater intrusion from rising sea levels, cyclone and storm surges, and upstream withdrawal of freshwater. The average estimated sodium intakes from drinking water ranged from 5 to $16 \mathrm{~g} /$ day in the dry season, compared with 0.6-1.2 $\mathrm{g} / \mathrm{day}$ in the rainy season. This resulted in the annual hospital prevalence of hypertension in pregnancy being higher in the dry season. [5]

Guidelines for dietary salt intake have been established by the World Health Organization (WHO), but no guidelines have been released for safe salinity levels in drinking water, except that sodium levels $>0.2 \mathrm{~g} / \mathrm{L}$ are unacceptable to taste. [6] High salinity levels in drinking water may have numerous direct and indirect impacts on health. In 2002 the WHO recognized health impacts of consumption of highly saline waters as a priority for investigation under its public health initiatives. [7].

High salinity levels have caused negative effects on plant growth globally. There exists a large influence of plant/crop damages and excessive salinity inhibits the growth of crop plants which include osmotic effects, as well as the direct toxicity caused by certain ions. [8]

Common practices for the removal of sulphate and calcium mainly consist of the use of coagulation/flocculation processes or reverse osmosis, which are either ineffective, costly or result in toxic by-products. Adsorption is a better alternative to remove such pollutants from water, giving the opportunity to recover and control the pollutant while regenerating the adsorbent. [9, 10-21]

Polyampholyte hydrogels (PAHs), which contain ionic components, otherwise known as ionic side groups, are 
commonly referred to as smart hydrogels, because of the reversible deformations. These could be swelling, bending, rotating or translating, which occurs when an external stimulus is applied. The repeating units of PAHs, which are positively and negatively charged, are the most suitable functional groups for the adsorption of various toxic ionic particles.

\section{EXPERIMENTAL}

Polyampholytes are synthesized hydrogels which were designed by radical polymerization of monomers at room temperature and allowed to bind. A cation and anion were used in combination with a crosslinking agent, an accelerator and an initiator. Different parameters namely, the molar ratio of cation to anion, dosage and time used to determine optimum parameters in a synthetic solution based on the absorption capacity of Sulphur. Seawater and the Potchefstroom municipality tap water were considered as polluted water sources to be treated using the synthesized polyampholytes. The various polyampholytes were synthetized by adapting a method previously reported $[9,22]$.

\section{A. Materials}

The following materials were used and were purchased from Rochell, SIGMA, ACE and Merck in South Africa.

i. 3-acrylamidopropyl-trimethylammonium-ATP as a cation.

ii. Acrylic acid-Aac as an anion.

iii. N,N'methylenebis-acrylamide (MBA) as a cross linker.

iv. Potassium persulfate (KPS) as an initiator.

v. N,N,N,N'-tetramethylethylenediamine (TEMED) as the accelerator.

vi. For the preparation of a synthetic solution: Sodium sulphate anhydrous

vii. Seawater was couriered from Cape Town.

viii. Water was taken from the tap for Potchefstroom municipality water.

\section{B. Synthesis Of Hydrogel And Synthetic Solution}

The synthesis of the polyampholyte was carried out at room temperature. Before the process was initiated, potassium persulfate (KPS) was diluted in deionized water (DW) to achieve a liquid solution of $2 \%(\mathrm{w} / \mathrm{v})$ and hence $2 \mathrm{~g}$ was diluted into $100 \mathrm{ml}$ of DW.

Five different cation to anion molar ratios were synthesized (3:1.7, 2.4:2.3, 1:1, 1.8:2.8, 1.2:3.4). In a $250 \mathrm{~mL}$ beaker, 0.28 mg MBA was diluted with $6 \mathrm{~mL}$ of $\mathrm{DW}$ and mixed with a magnetic stirrer to ensure the complete mixing and dissolving of the MBA. By means of a pipette the different volumes of cation (ATP) and anion (Aac) were added, based on the different ratios as indicated in sTable 1.
TABLE I

POLYAMPHOLYTE HYDROGEL CALCULATED VOLUMES BASED ON MOLAR RATIOS

\begin{tabular}{|l|l|l|l|l|}
\hline $\begin{array}{l}\text { Polymer } \\
\text { name }\end{array}$ & $\begin{array}{l}\text { Cation } \\
\text { ratio }\end{array}$ & $\begin{array}{l}\text { Anion } \\
\text { ratio }\end{array}$ & $\begin{array}{l}\text { ATP } \\
\text { volume } \\
{[\mathrm{ml}]}\end{array}$ & $\begin{array}{l}\text { Aac } \\
\text { volume } \\
{[\mathrm{ml}]}\end{array}$ \\
\hline $\mathrm{A}$ & 3 & 1.7 & 4.856 & 0.760 \\
\hline $\mathrm{B}$ & 2.4 & 2.3 & 4.440 & 1.176 \\
\hline $\mathrm{C}$ & 1 & 1 & 4.400 & 1.216 \\
\hline $\mathrm{D}$ & 1.8 & 2.8 & 3.928 & 1.688 \\
\hline $\mathrm{E}$ & 1.2 & 3.4 & 3.150 & 2.466 \\
\hline
\end{tabular}

The initiator (KPS) of volume $3.2 \mathrm{~mL}$ and the accelerator (TEMED) of volume $0.5 \mathrm{~mL}$ were added to the solution. The solution was mixed for approximately five minutes on a magnetic stirrer and the magnetic stirrer was removed and the beaker with the solution was placed in the incubator for a duration of 24 hours at $25^{\circ} \mathrm{C}$ and $90 \mathrm{rpm}$, which allows for the total formation of a hydrogel. This process was repeated for the different molar ratios referred as polymer A-E as indicated in Table 1. Fig 1. bellow illustrates the chemical interaction for preparation of the polyampholytes.

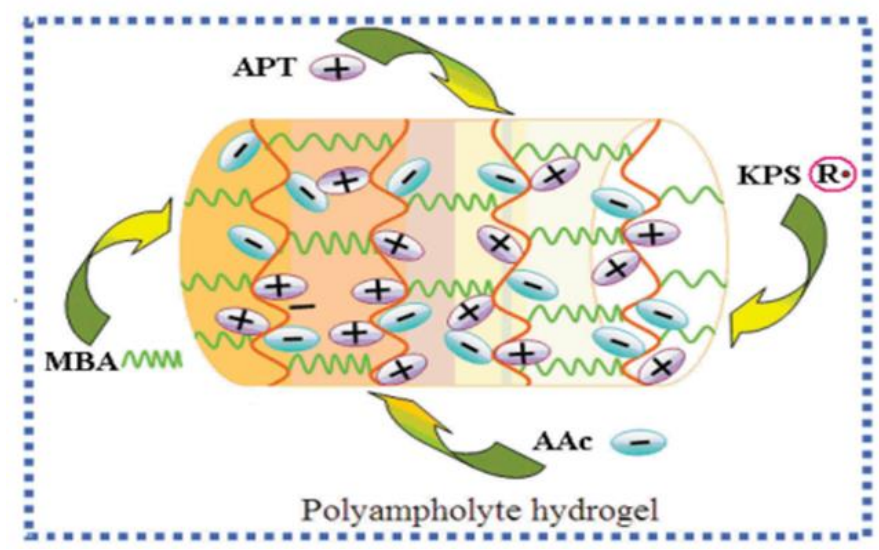

Fig 1

Fig1. Represents The Polyampholyte hydrogel configuration with the cross-linker taken from Kudaibergenov \& Sigitov [22] The formed polyampholytes hydrogels, after 24 hours of reaction time, were then cut up into +- 4-5 $\mathrm{mm}$ cubes and deionized water (DW) was added to the beakers and stored for $24 \mathrm{~h}$ at room temperature. This allowed for the dilution of the unreacted species in the DW. The hydrogels and DW mixture were then filtered after the 24 hours and the process for the removal of unreacted species was repeated for a duration of seven days.

On the seventh day of filtration the wet hydrogels were then placed in the incubator for drying. The hydrogels were dried for 24 hours at $40^{\circ} \mathrm{C}$. These polyampholyte hydrogels were then crushed by a hand stone crusher to form a powder.

A $1 \mathrm{~L}$ base synthetic solution of $1000 \mathrm{ppm}$ sulphate was made by dissolving Sodium sulphate anhydrous into $1 \mathrm{~L} \mathrm{DW}$. For the adsorption experiments, working solutions of $50 \mathrm{ppm}$ concentration were prepared. 


\section{Characterization Of Hydrogel}

The powdered hydrogels were sent for analyses using Fourier-transform infrared spectroscopy (FTIR) and Scanning Electron Microscopy with Energy Dispersive X-Ray Spectrometer (SEM/EDS).

\section{Absorption experiments}

To determine the best polyampholyte ratio for the removal of sulphate from solution, $0.3 \mathrm{~g}$ of each molar ratio was dosed into a $100 \mathrm{~mL}$ of synthetic solution in a $250 \mathrm{~mL}$ Erlenmeyer flask at room temperature of $25^{\circ} \mathrm{C}$ for a duration of 1 hour in an incubator at $160 \mathrm{rpm}$ and the optimum ratio was evaluated. Similarly, various masses $(0.1 \mathrm{~g}, 0.2 \mathrm{~g}, 0.3 \mathrm{~g}, 0.4 \mathrm{~g})$ of the optimum ratio were dosed into a $100 \mathrm{~mL}$ of synthetic solution in a $250 \mathrm{~mL}$ Erlenmeyer flask at room temperature of $25^{\circ} \mathrm{C}$ for a duration of 1 hour in an incubator at $160 \mathrm{rpm}$ and the optimum dosage was evaluated. In a likewise fashion the optimum contact time was determined considering sulphate exposure to the polyampholytes for the following time intervals, $25,50,75$, 100, 125 mins. Each of these were based on the turbidimetric sulphate results and were centrifuged prior to test. All tests were conducted in duplicate.

\section{E. Experimental Analysis And Models}

The sulphate percentage removals were determined using the following formula:

$\%$ Absorption $=\frac{C_{0}-C_{e}}{C_{0}} \times 100$

Where $\mathrm{C}_{\mathrm{o}}$ is the initial concentration in $\mathrm{mg} / \mathrm{L}$ of sulphate and $\mathrm{C}_{\mathrm{e}}$ is the average equilibrium concentration after dosage.

The two kinetic models used were the pseudo-first-order kinetic model and the pseudo-second-order kinetic model.

The pseudo-first-order kinetic model:

$\log \left(q_{\theta}-q_{t}\right)=\log \left(q_{\theta}\right)-k_{1} \frac{t}{2.303}$

The pseudo-second-order kinetic model:

$\frac{t}{q_{t}}=\frac{1}{\left(k_{2} q_{e}^{2}\right)}+\frac{1}{q_{e}} t$

With q given as:

$q_{t}=\frac{\left(C_{o}-C_{t}\right) V}{m}$

$\mathrm{V}$ is the volume in liters, $\mathrm{m}$ is the mass in $\mathrm{mg}$ and $\mathrm{q}$ is dimensionless. The two constant achieved are $\mathrm{K}_{1}$ and $\mathrm{K}_{2}$ based on the linear regression and can be used in further approximations.

\section{RESULTS AND DISCUSSION}

\section{A. FTIR Analysis}

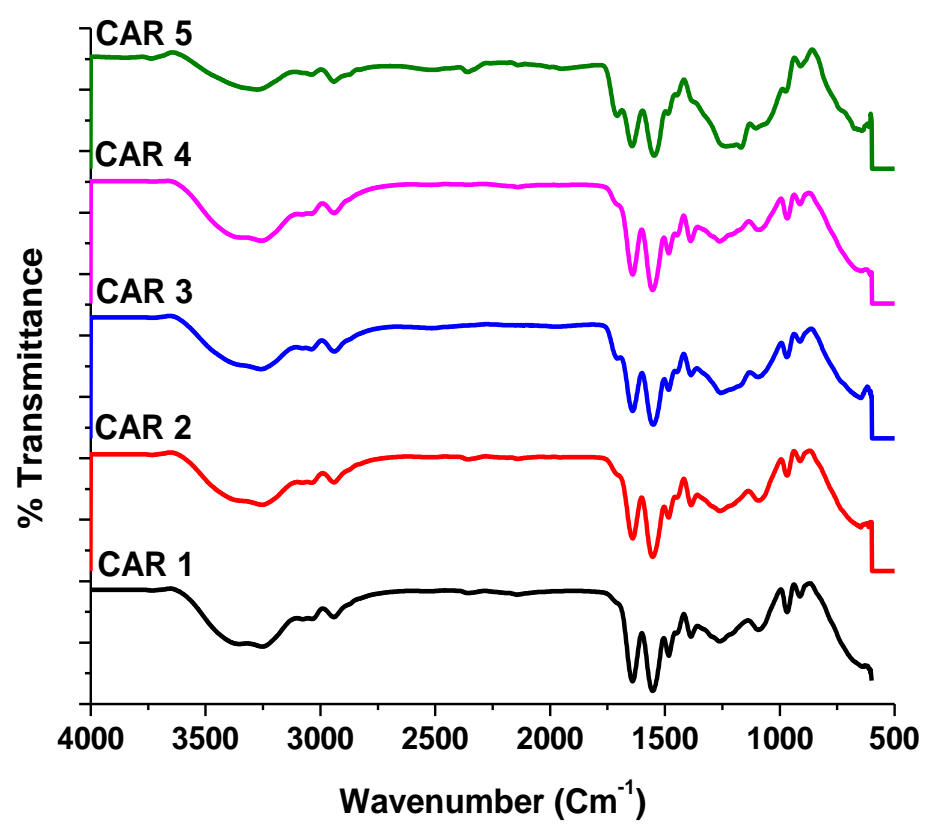

Fig. 2

Fig 2. Represents the FTIR functional group graph characterization results obtained. The synthesis of the five absorbents of different cationic and anionic ratios have shown a common trend in peaks indicating consistency in its functional groups. The different ratios are shown with CAR 1 being most cationic and CAR 5 being the most anionic ratio The peaks indicate good absorption capacities. In the range 3700-3200 $\mathrm{cm}^{-1}$ a clear broad O-H peak is observed between 3650-3200 $\mathrm{cm}^{-1}$ showing the presence of the alcohol functional group. Amine and amide functional groups of $\mathrm{N}-\mathrm{H}$ bonds maybe present within the $3500-3300 \mathrm{~cm}^{-1}$. Within the range $3200-2700$ $\mathrm{cm}^{-1}$ the presence of a small peak may correspond to alkane, aryl, vinyl and carboxylic acid O-H bonds functional groups. In the range $1680-1450 \mathrm{~cm}^{-1}$ wavenumbers, there are steepest peaks with a clear distinction which can be ascribed to $\mathrm{C}-\mathrm{C}=\mathrm{C}$ symmetric stretch and $\mathrm{C}=\mathrm{O}$ stretch functional groups which have high adsorption affinity. [23] 
B. SEM Analysis

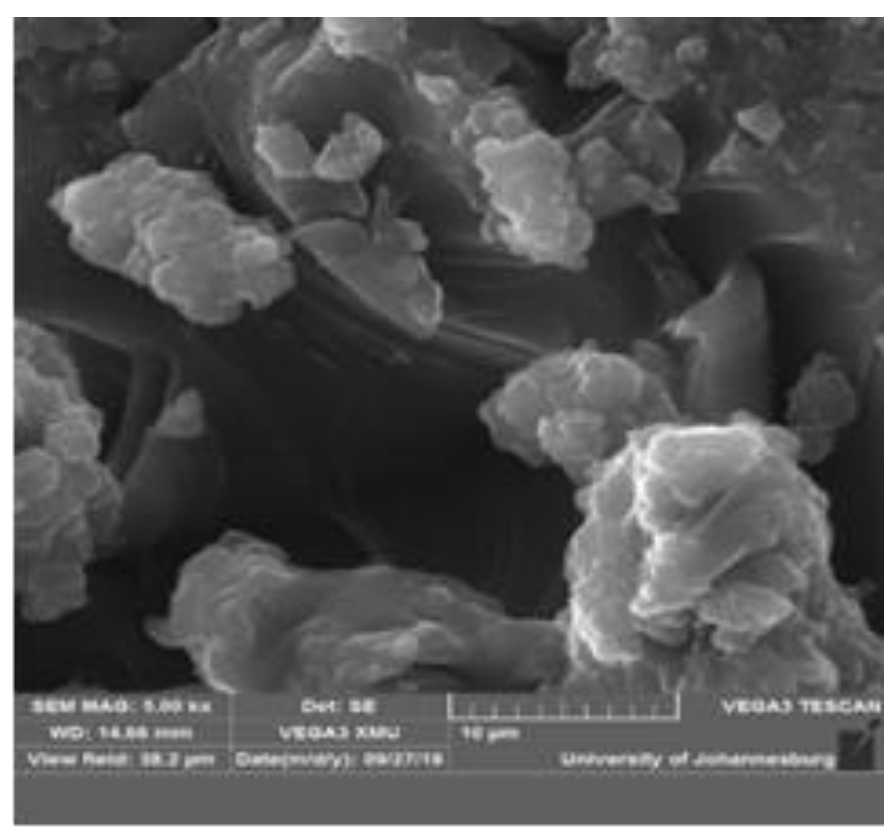

Fig 3 (a)

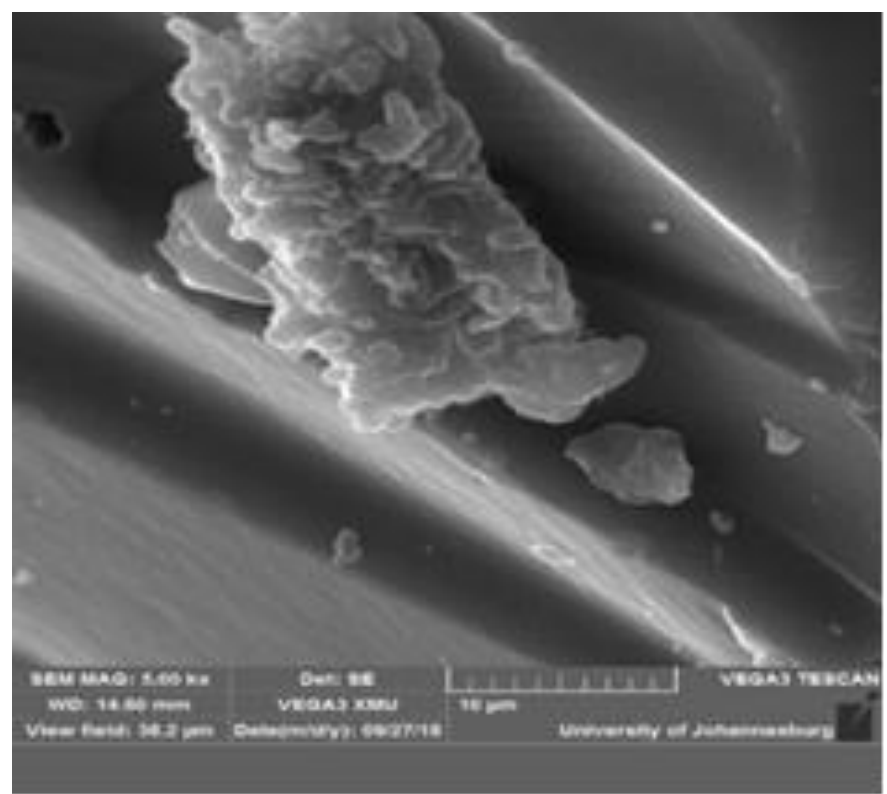

Fig 3 (b)

Fig.3 indicates two absorbents SEM analysis with (a) being the most cationic absorbent and (b) being the most anionic absorbent.

A clear difference in the morphology of the polymers can be observed as the most cationic polyampholyte exhibits a rough surface while the most anionic polyampholyte exhibits a more smooth surface The difference in morphology can be ascribed to the variation in the ratio of the ingredients that certainly affected the chemical reaction; however, there was not major difference likely to significantly affect the adsorption capacity.
C. EDS Analysis

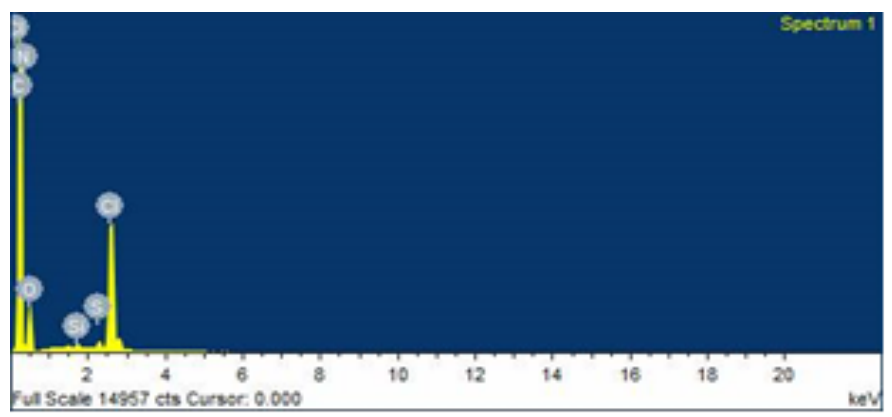

Fig 4 (a)

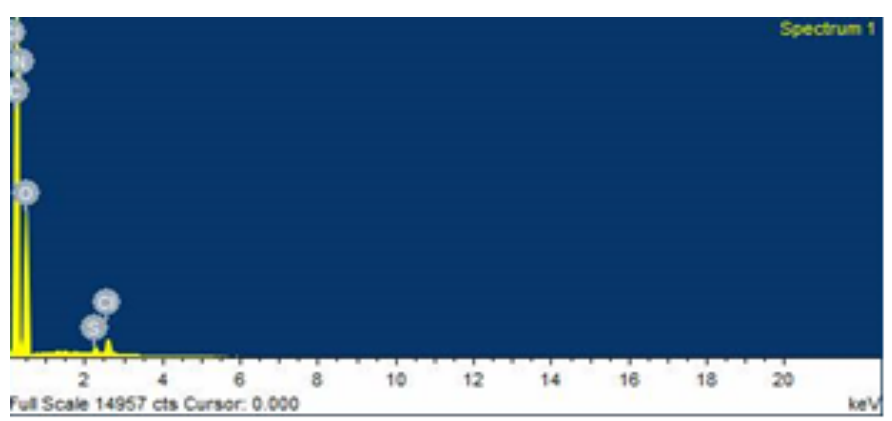

Fig 2 (b)

Fig. 4 indicates two absorbents EDS spectra analysis with (a) being the most cationic absorbent and (b) being the most anionic absorbent.

A consistency in the elements present are noted as expected with different peak levels indicating that the desired output based on the ions expected for cationic and anionic compounds and hence illustrating the different range in charges. An energy total level ranged between 6-7 keV which is suitable for absorption. The energy level per compound is also consistent whereby at around $2.5 \mathrm{keV}, \mathrm{Cl}^{-}$is observed and at around 2.3 $\mathrm{keV}, \mathrm{S}^{2-}$ can be seen. The steep $\mathrm{Cl}^{-}$curve in (a) confirms the cationic capacity of (a) compared to (b).

\section{Tubidimetric Sulphate Analysis}

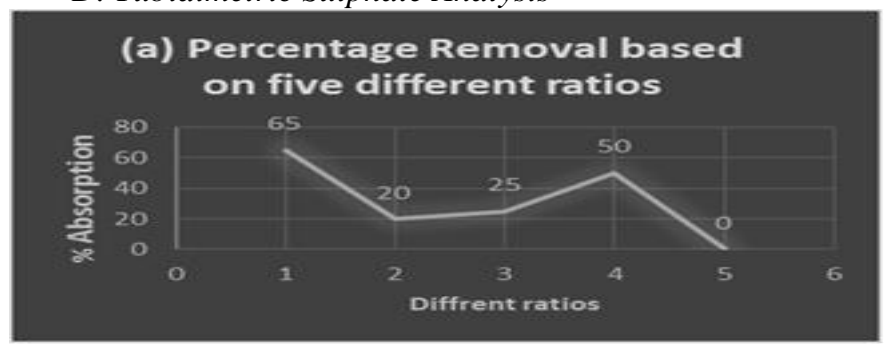

Fig 5 (a)

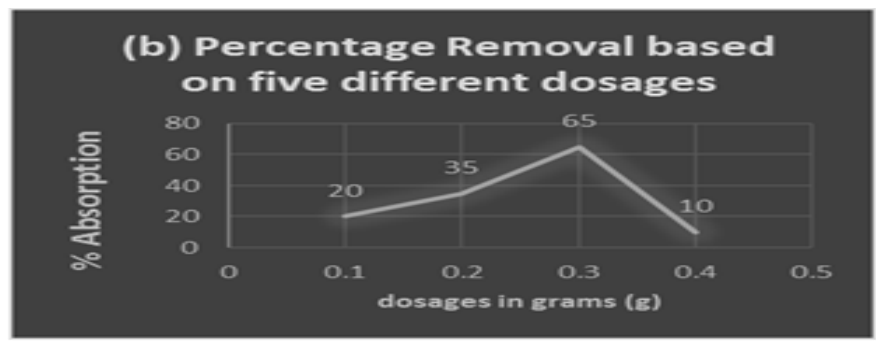

Fig 5 (b) 


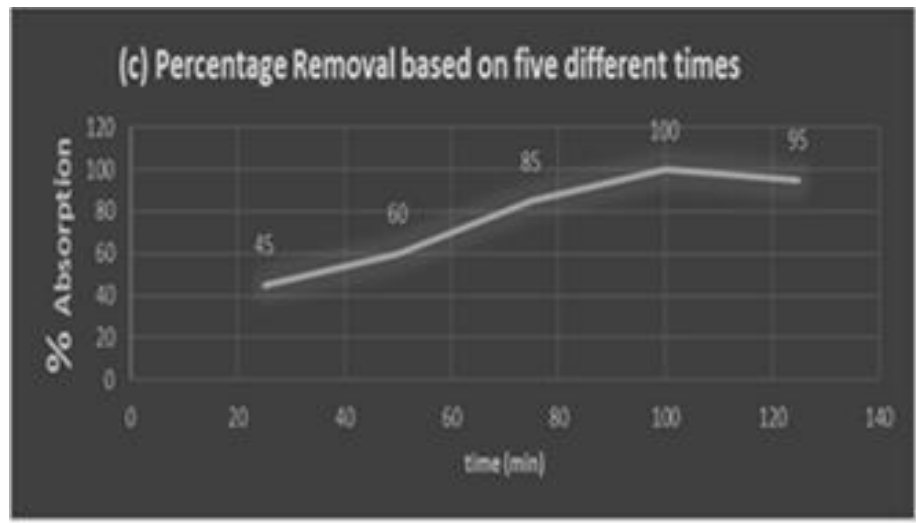

Fig 5 (c)

The Tubidimetric sulphate analysis for the five different cationic and anionic absorbents indicated a $65 \%$ removal of sulphate for ratio one being the most cationic compound with a ratio of 3:1.7 cation to anion as indicated in Fig. 3(a). The investigation of the effect of adsorbent dosage showed (Fig. 3(b)) a dosage of $0.3 \mathrm{~g}$ was sufficient to achieve a higher removal rate corresponding to $65 \%$ removal of sulphate. The investigation of the effect of time on the removal of sulphate showed that $1 \mathrm{~h} 40$ mins exposure time was enough to achieve $100 \%$ removal of sulphate from solution.

\section{E. Kinetic Models}

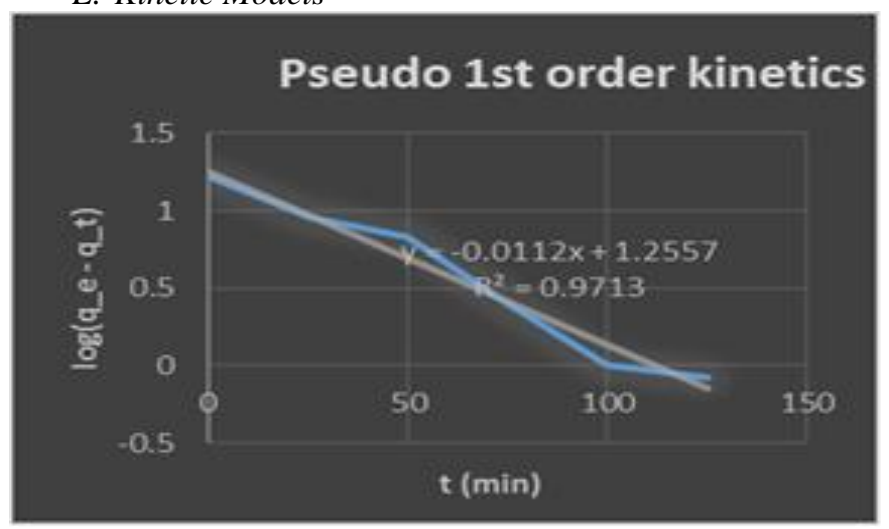

Fig 6 (a)

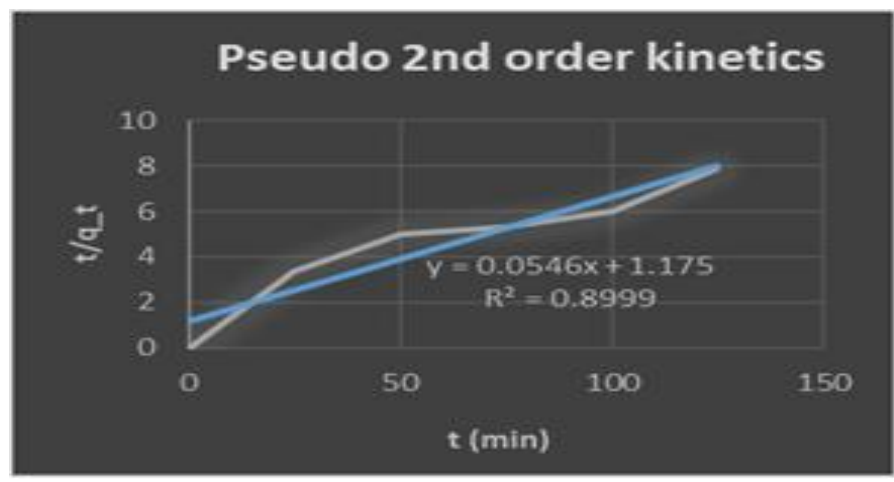

Fig 3 (b)

A close approximation of the kinetics models indicates a satisfactory trend line with a better fit for the Pseudo first order model having a regression of 0.97 . The constant values for the models were calculated as $\mathrm{k}_{1}=0.025794$ and $\mathrm{k}_{2}=0.003064$ for the pseudo first and second order kinetic model respectively. The relative fitness of the pseudo second order kinetic model to the adsorption data also shows that the adsorption of sulphate by the polyampholyte occurs through a combination of physical and chemical mechanisms as expected [24-36].

\section{F. Practical Test Analysis}
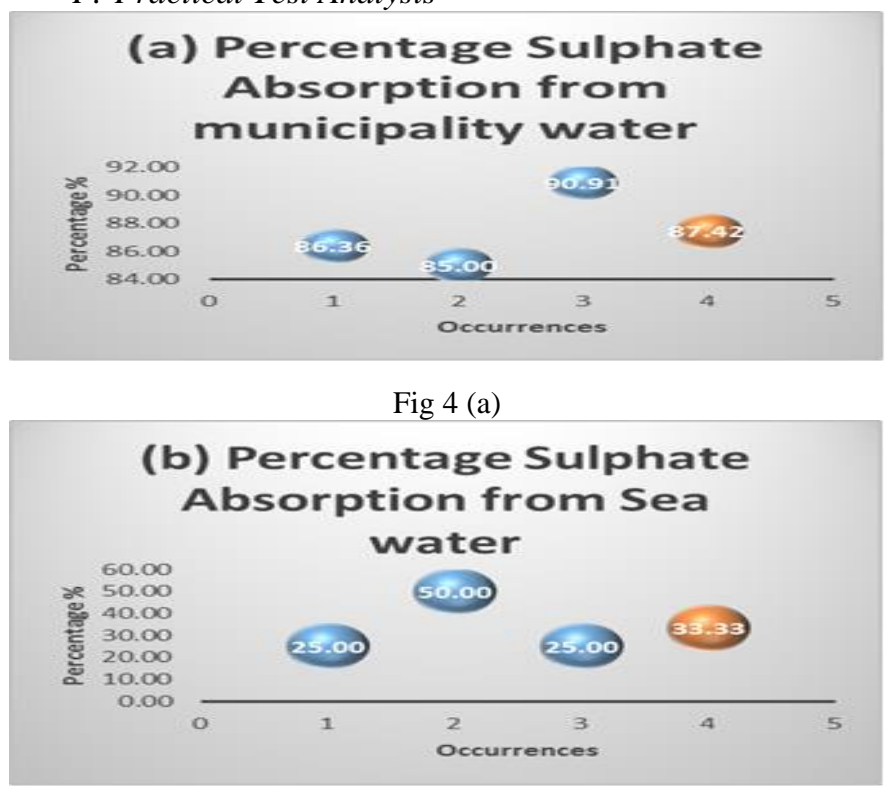

Fig 7 (b)

Good sulphate extraction capacities are observed and can be seen in Fig. 7 (a) and (b). Fig. 7(a) indicates absorption capacities based on samples of the Potchefstroom tap water which contained a sulphate content bellow the South African standards for acceptable water but a high content of $110 \mathrm{mg} / \mathrm{L}$ an average absorption capacity of $82.42 \%$ was achieved reducing the sulphate content to just above $10 \mathrm{mg} / \mathrm{L}$. Fig. 7(b) indicates the rate of absorption of sulphate from Sea water samples containing $2000 \mathrm{mg} / \mathrm{L}$ of sulphate; the polyampholyte was in this occasion able remove $33.33 \%$ of sulphate from sea water which is however low but can be optimized further with a specific time and dosage analysis.

\section{CONCLUSION}

The absorption capacities of Polyampholytes have shown phenomenal characteristics towards the reduction of sulphate content in water without being energy intensive. This can be seen as a best and optimal solution mechanism towards further development in the reduction salt from water. The cation and anion ratios facilitated the exchange of ions allowing for the absorption by ions. A more cationic hydrogel has exhibited encouraging adsorption capacity for the reduction of sulphate in water, this is due to the negative charge carried by sulphates. Further improvement of the polyampholyte is therefore required for application in the treatment of solutions with high salinity such as sea water.

\section{ACKNOWLEDGMENT}

The Authors would like to thank the University of Johannesburg for helping with the continual analysis of SEM and FTIR data. We would also like to thank all those who have 
helped and assisted in this research by all ways possible.

\section{REFERENCES}

[1] Azaizeh, H. \& Steudle, E. 1991. Effects of Salinity on Water Transport of Excised Maize (Zea mays L.) Roots. Plant Physiol. 97(3):1136-1145. https://doi.org/10.1104/pp.97.3.1136

[2] Chelin, M.J. 2000. An assessment of water management issues facing the coal minning industry of the Witbank and Middelburg dam. Univ. Pretoria.

[3] Fosso-Kankeu, E., Waanders, F., Maloy, E., \& Steyn, B. 2016. Reduction of salinity and hardness of water using copolymerized biopolymers. Drebenstedt, Carsten, Paul, Michael (eds.). (Mining Meets Water - Conflicts and Solutions):995-1001.

[4] Khan, A.E., Ireson, A., Kovats, S., Mojumder, S.K., Khusru, A., Rahman, A., \& Vineis, P. 2011. Drinking water salinity and maternal health in coastal Bangladesh: Implications of climate change. Environ. Health Perspect. 119(9):1328-1332. https://doi.org/10.1289/ehp.1002804

[5] Kudaibergenov, S.E. \& Sigitov, V.B. 1999. Swelling, shrinking, deformation, and oscillation of polyampholyte gels based on vinyl 2-aminoethyl ether and sodium acrylate. Langmuir. 15(12):4230-4235. https://doi.org/10.1021/la981070a

[6] Neyret, S., Ouali, L., Candau, F., \& Pefferkorn, E. 1995. Adsorption of polyampholytes on polystyrene latex: Effect on colloid stability. J. Colloid Interface Sci. 176(1):86-94. https://doi.org/10.1006/jcis.1995.0010

[7] Nicolaisen, B. 2003. Developments in membrane technology for water treatment. Desalination. 153(1-3):355-360. https://doi.org/10.1016/S0011-9164(02)01127-X

[8] Singh, R.N. \& Porter, I. 2012. Incidence of Barium Pollution in Mine Water Discharge in an Underground Coal Mine. :433-447.

[9] The Department Of Water Affairs And Forestry. 2004. Overview of the South African Water Sector. Natl. water Resour. Strateg. 1:1-35.

[10] E. Fosso-Kankeu, A. Mulaba-Bafubiandi, B.B. Mamba, T.G. Barnard, Indigenous microorganism strains as bio-extractants of $\mathrm{Ca}, \mathrm{Fe}$ and $\mathrm{Mg}$ from metallurgical and mine drainages. The Southern African Institute of Mining and Metallurgy, Hydrometallurgy Conference 2009. Symposium Series S54, pp 93-100, 2009.

[11] E. Fosso-Kankeu, A.F. Mulaba-Bafubiandi, B.B. Mamba, L. Marjanovic, and T.G. Barnard, Optimising the removal by $\mathrm{b}$ subtilis and $\mathrm{b}$ bacterium of metals found around mining areas: evaluation of the effect of physical and physiological parameters. In: Water Institute of Southern Africa \& International Mine Water Association: Proceedings, International Mine Water Conference. International Mine Water Association Conference, Pretoria 2009. ISBN: 978-0-9802623-5-3. 2009.

[12] E. Fosso-Kankeu, A. Mulaba-Bafubiandi, B.B. Mamba, T.G. Barnard, Mitigation of $\mathrm{Ca}, \mathrm{Fe}$, and $\mathrm{Mg}$ loads in surface waters around mining areas using indigenous microorganism strains. Journal of Physics and Chemistry of the Earth, Vol. 34, pp. 825-829, 2009. https://doi.org/10.1016/j.pce.2009.07.005

[13] E. Fosso-Kankeu, A. Mulaba-Bafubiandi, B.B. Mamba, L. Marjanovic, T.G. Barnard, A comprehensive study of physical and physiological parameters that affect biosorption of metal pollutants from aqueous solutions. Journal of Physics and Chemistry of the Earth, Vol. 35, pp. 672-678, 2010. https://doi.org/10.1016/j.pce.2010.07.008

[14] E. Fosso-Kankeu, A.F. Mulaba-Bafubiandi, B.B. Mamba and T.G. Barnard, Prediction of metal-adsorption behaviour in the remediation of water contamination using indigenous microorganisms. Journal of Environmental Management. Vol. 92, no. 10, pp. 2786-2793, 2011. https://doi.org/10.1016/j.jenvman.2011.06.025

[15] H. Mittal, E. Fosso-Kankeu, Shivani B. Mishra, Ajay K. Mishra, Biosorption potential of Gum ghatti-g-poly (acrylic acid) and susceptibility to biodegradation by B. subtilis. International Journal of Biological Macromolecules. Vol. 62, pp. 370-378, 2013. https://doi.org/10.1016/j.ijbiomac.2013.09.023

[16] E. Fosso-Kankeu, L. Simelane, Kinetic study of methylene blue removal by Gram-negative and Gram-positive bacteria. International Multi-conference on Education, Law, Environment and Metallurgical Engineering (IMELEME' 2013); 27-28 November 2013,
Johannesburg-South Africa. (Award Winning Paper). Editors: Sandhu S and Muzenda E. ISBN: 978-93-82242-50-5. 2013.

[17] E. Fosso-Kankeu, F. Waanders, Metal Ions Adsorption Affinity of Clay Materials from the North West Province of South Africa. An Interdisciplinary Response to Mine Water Challenges. International Mine Water Conference, August 2014 Xuzhou China. Editors, Sui, Sun \& Wang (Eds). 2014 China University of Mining andTechnology Press, Xuzhou, ISBN: 978-7-5646-2437-8. Pp374-378. 2014.

[18] F. Waanders, M. Nel, E. Fosso-Kankeu, Adsorption potential of bentonite clay and attapulgite applied for the desalination of sea water. $6^{\text {th }}$ International Conference on Green Technology, Renewable Energy and Environmental Engineering (ICGTREEE'2014). 27-28 November 2014, Cape Town-South Africa. Editors: Muzenda E. and Sandhu S. ISBN: 978-93-84468-08-8. Pp 275-279. 2014.

[19] E. Fosso-Kankeu, F. Waanders, M. Reitz, Selective adsorption of heavy and light metals by natural zeolites. $6^{\text {th }}$ International Conference on Green Technology, Renewable Energy and Environmental Engineering (ICGTREEE'2014). 27-28 November 2014, Cape Town-South Africa. (Award Winning Paper). Editors: Muzenda E. and Sandhu S. ISBN: 978-93-84468-08-8. Pp 271-274. 2014.

[20] E. Fosso-Kankeu, F. Waanders, C. Fraser, Bentonite clay adsorption affinity for anionic and cationic dyes. $6^{\text {th }}$ International Conference on Green Technology, Renewable Energy and Environmental Engineering (ICGTREEE'2014). 27-28 November 2014, Cape Town-South Africa. Editors: Muzenda E. and Sandhu S. ISBN: 978-93-84468-08-8. Pp 257-260. Pp 257-260. 2014.

[21] E. Fosso-Kankeu, A.F. Mulaba-Bafubiandi, Challenges in the escalation of metal-biosorbing processes for water treatment: applied and commercialized technologies. African Journal of Biotechnology. Vol. 13, no. 17, pp. 1756-1771, 2014. https://doi.org/10.5897/AJB2013.13311

[22] UNICEF \& WHO. 2017. Progress on Drinking Water, Sanitation and Hygiene.

[23] United Nations Development Programme. 2016. Human development report 2016. , United Nations Development Program.

[24] E. Fosso-Kankeu, F. Waanders, and C. Laurette Fourie, Surfactant Impregnated Bentonite Clay for the Adsorption of Anionic Dyes. $7^{\text {th }}$ International Conference on Latest Trends in Engineering and Technology (ICLTET' 2015), November 26-27, 2015 Irene, Pretoria (South Africa). Editors: E. Muzenda and T Yingthawornsuk. ISBN: 978-93-84422-58-5. 2015.

[25] E. Fosso-Kankeu, H. Mittal, S.B. Mishra, A.K. Mishra, Gum ghatti and acrylic acid based biodegradable hydrogels for the effective adsorption of cationic dyes. Journal of Industrial and Engineering Chemistry. Vol. 22, pp. 171-178, 2015. https://doi.org/10.1016/j.jiec.2014.07.007

[26] E. Fosso-Kankeu, F.B. Waanders, F.W. Steyn, The Preparation and Characterization of Clay-Biochar Composites for the Removal of Metal Pollutants. $7^{\text {th }}$ International Conference on Latest Trends in Engineering and Technology (ICLTET' 2015), November 26-27, 2015 Irene, Pretoria (South Africa). Editors: E. Muzenda and T Yingthawornsuk. ISBN: 978-93-84422-58-5. 2015.

[27] E. Fosso-Kankeu, E. Maloy, and F. Waanders, Preparation of Ethyl Acrylate - Guar Gum Copolymer for the Mitigation of Water Hardness. $7^{\text {th }}$ International Conference on Latest Trends in Engineering and Technology (ICLTET' 2015), November 26-27, 2015 Irene, Pretoria (South Africa). Editors: E. Muzenda and T Yingthawornsuk. ISBN: 978-93-84422-58-5. 2015.

[28] E. Fosso-Kankeu, H. Mittal, F. Waanders, S.S. Ray, Performance of synthesized hybrid hydrogel nanocomposite applied for the removal of metal ions from aqueous solutions. In: Drebenstedt, C. \& Paul, M.: IMWA 2016 - Mining Meets Water - Conflicts and Solutions. - p. 850 857; Freiberg/Germany (TU Bergakademie Freiberg). 2016.

[29] E. Fosso-Kankeu, F. Waanders, E. Maloy, Copolymerization of ethyl acrylate onto guar gum for the adsorption of $\mathrm{Mg}$ (II) and $\mathrm{Ca}$ (II) ions. Desalination and Water Treatment. doi: 10.1080/19443994.2016.1165147: pp. 1-10, 2016.

[30] E. Fosso-Kankeu, F. Waanders, C.L. Fourie, Adsorption of Congo Red by surfactant-impregnated bentonite clay. Desalination and Water Treatment. doi: 10.1080/19443994.2016.1177599: pp. 1-9, 2016.

[31] E. Fosso-Kankeu, A.F. Mulaba-Bafubiandi, L.A. Piater, M.G. Tlou, Cloning of the cnr operon into a strain of Bacillaceae bacterium for the 
development of a suitable biosorbent. World Journal of Microbiology and Biotechnology. DOI 10.1007/s11274-016-2069-5. 2016.

[32] E. Fosso-Kankeu, H. Mittal, S. Marx and S.S. Ray, Hydrogel-based bioflocculants for the removal of organic pollutants from biodiesel wastewater. Journal of Polymer and Environment. DOI 10.1007/s10924-016-0870-8. 2016.

[33] E. Fosso-Kankeu, H. Mittal, F. Waanders, S.S. Ray, Thermodynamic properties and adsorption behaviour of hydrogel nanocomposites for cadmium removal from mine effluents. Journal of Industrial and Engineering Chemistry. Vol. 48, pp. 151-161, 2017. https://doi.org/10.1016/j.jiec.2016.12.033

[34] E. Fosso-Kankeu, F.B. Waanders, F.W. Steyn, Removal of $\mathrm{Cr}(\mathrm{VI})$ and $\mathrm{Zn}$ (II) from an aqueous solution using an organic-inorganic composite of bentonite-biochar-hematite. Desalination and Water Treatment. Vol. 59, pp. 144-153, 2017.

[35] E. Fosso-Kankeu, 2018. Synthesized af-PFCl and GG-g-P(AN)/TEOS hydrogel composite used in hybridized technique applied for AMD treatment. Journal of Physics and Chemistry of the Earth. 2018.

[36] A. Leudjo Taka, E. Fosso-Kankeu, K. Pillay, X. Yangkou Mbianda, Removal of cobalt and lead ions from wastewater samples using an insoluble nanosponge biopolymer composite: Adsorption isotherms, kinetics, thermodynamics and regeneration studies. Environmental Science and Pollution Research. 2018.

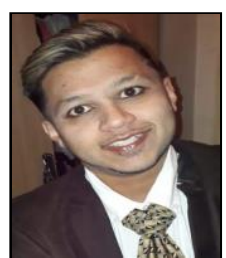

Varachia H. Hasan is a Bachelors of Engineering in Chemical Engineering student at the North West University, South Africa. This research is attained from his final year research project. He is continuing research in the field of absorption and extraction capacities of hydrogels with specific interest in polyampholytes 